\title{
Veröffentlichungen
}

der Vereinigung der Deutschen Staatsrechtslehrer

Heft 17

\section{Die verfassungsrechtliche Stellung der politischen Parteien im modernen Staat}

\section{Das Verwaltungsverfahren}

\author{
Berichte \\ ron \\ Konrad Hesse und Gustav E. Kafka \\ K. A. Bettermann und Erwin Melichar \\ und \\ Auszug aus der Aussprache zu den Berichten \\ in den Verbandlungen der Tagung der deutschen Stantechtelebrer \\ zu Wien am 9. und 10. Oktober 1958
}

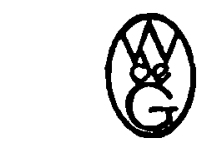

$$
\text { Berlin } 1959
$$

Walter de Gruyter \& Co.

als G. J. Crechen'uche verlaghandlung $I$ J. Guttentag, veringouchbandlung, I Geore Reimor I Karl J. Trabner I velt ¿ Comp. 
Archiv.Nr. 248959

Dalz und Druck: Rerliner Buchdructerel „Ualos" GmbB, Berlin SW 63

Alle Mechte, elocoblieslich des Rechtes der Borotellang

ron folukoples und Mikrofimed, vorbebalten. 